Cahiers $d u$ MONDE RUSSE

\section{Cahiers du monde russe}

Russie - Empire russe - Union soviétique et États indépendants

45/3-4 | 2004

Varia

\title{
Timur Beisembiev, The life of Alimqul. A native chronicle of nineteenth-century Central Asia
}

\author{
Stéphane A. Dudoignon
}

\section{OpenEdition}

\section{Journals}

Édition électronique

URL : https://journals.openedition.org/monderusse/4219

DOI : 10.4000/monderusse.4219

ISSN : $1777-5388$

Éditeur

Éditions de l'EHESS

\section{Édition imprimée}

Date de publication : 1 juillet 2004

Pagination : 741-744

ISBN : 2-7132-2009-2

ISSN : $1252-6576$

Référence électronique

Stéphane A. Dudoignon, «Timur Beisembiev, The life of Alimqul. A native chronicle of nineteenthcentury Central Asia », Cahiers du monde russe [En ligne], 45/3-4 | 2004, mis en ligne le 03 juin 2009, consulté le 04 septembre 2022. URL : http://journals.openedition.org/monderusse/4219; DOI : https://doi.org/10.4000/monderusse.4219

Ce document a été généré automatiquement le 4 septembre 2022.

Tous droits réservés 


\title{
Timur Beisembiev, The life of Alimqul. A native chronicle of nineteenth-century Central Asia
}

\author{
Stéphane A. Dudoignon
}

\section{RÉFÉRENCE}

Timur BEISEMBIEV, The life of Alimqul. A native chronicle of nineteenth-century

Central Asia. Londres-New York, Routledge Curzon 2003, XIV-116-[2]-LXXXIII-196-LIX p., annexes, bibliogr., index (Central Asia Research Forum)

1 Le présent ouvrage propose l'édition et la traduction anglaise d'une chronique en persan intitulée dans les catalogues Ta'rkh-i 'Ālimqul-i amirr-i lashkar ("Chronique de 'Ālimqul, duc de l'ost ») et rédigée très vraisemblablement par un juriste et poète de cour du Ferghana, Mullā Muhammad Yūnus Jān Tāshkand, connu également sous son nom de plume (en persan takhallus) de Tāyib (« Le Pénitent »), né vers 1829-1830, mort entre 1902 et 1914. L'édition a été établie d'après un manuscrit copié dans le district (uezd) d'Andijan, à l'est de la vallée de Ferghana, en 1902-1903 et aujourd'hui conservé sous la cote 12136 à l'Institut Biruni des études orientales de l'Académie des sciences d'Ouzbékistan, à Tashkent. Ce manuscrit a été acquis par l'institut en juin 1969 auprès d'un particulier de la ville de Marghilan, autre cité du Ferghana, Ahmadjan MuhammadBabaev. Le texte consiste en une biographie de 'Ālimqul (c. 1833-1865), éminente figure de l'appareil militaire et politique du khanat de Kokand, qu'il gouverna de facto entre 1863 et 1865, c'est-à-dire dans les premières années de la conquête russe de la Transoxiane.

2 L'auteur, dont le nom n'est pas mentionné dans le texte, est un ancien mirrzābāš (secrétaire principal) du gouverneur de Tachkent et, à ce titre, il a notamment pris part à la collecte des impôts fonciers. Il est identifié par Timur Beisembiev grâce à un très érudit et subtil recoupement de plusieurs chroniques ferghanaises du tournant des XIX et 
$\mathrm{xx}^{\mathrm{e}}$ siècles. Son profil est celui d'un lettré et juriste de la charia : selon le Ta'rïkh-i jadìda (par Muhammad Sālih Khwāja Tāškandī, Institut Biruni, n 7791), Mullā Muhammad Yūnus Jān exerçait à la fin des années 1880 une charge de juge ( $q \bar{a} z)$ dans la ville de Kokand, alors annexée au Turkestan russe. Le Ta'rikh-i 'Âlimqul révèle en outre la proximité de son auteur avec Ya'qūb Beg (1820-1877), compagnon de 'Ālimqul et maître du Turkestan oriental dans les années 1860-1870 - Mullā Muhammad Yūnus Jān a gouverné entre 1866 et 1877 la ville de Yarkand, où il a laissé le souvenir d'un administrateur soucieux du respect des normes de la charia. Mullā Muhammad Yūnus Jān Tāshkandī est également l'auteur d'un Hadā'iq al-anwār (Institut Biruni, n’ 596/II), une brève histoire des khans de Kokand rédigée vers 1885 ou 1886, lorsque l'auteur était âgé de 57 ans.

Le propos essentiel du Ta'rikh-i 'Ālimqul, comme celui d'un autre ouvrage du même auteur, le Tuhfat-i tāyibī (« Présent de Tāyib », texte de 21 folios écrit entre 1900 et 1901), est une dénonciation des dissensions entre les princes régnants de Kokand Khudāyār Khān et Malla Khān dans les années 1850-1860, lesquelles devaient s'avérer fatales à l'unité du khanat et à ses facultés de résistance face à l'avancée militaire de la Russie. Il est à noter que ces deux textes ont été rédigés sur la commande d'une seule et même personne, Mullā Šīr Muhammad Mīrzā, fils de 'Ālimqul. Analysant les causes de cette progression, l'auteur exhorte la population du Ferghana à accepter la domination d'un État non musulman et à assimiler la civilisation russe. De ce point de vue, le Ta'rikh-i 'Ālimqul doit être rattaché à la floraison de littérature biographique et autobiographique qui, au tournant des $\mathrm{XIX}^{\mathrm{e}}$ et $\mathrm{Xx}^{\mathrm{e}}$ siècles, se penche sur les causes de la soumission de la Transoxiane à la domination d'un État chrétien.

Il s'inscrit également dans une tendance largement représentée en Asie centrale à la fin du $x{ }^{e}$ siècle, et qui oppose à la théorie du djihad celle de la coopération avec les autorités coloniales non musulmanes (voir les études de l'historien japonais Masami Hamada sur les déclinaisons politiques de la notion de « devoir du sel » au Xinjiang après l'établissement de la domination des Qing). Bien que centrée sur la figure d'un représentant du corps des umarā (dignitaires militaires) des piémonts du Ferghana, le récit auquel nous avons à faire ici, dû à la plume d'un juriste de la charia issu des milieux urbains de la vallée, partage de nombreuses caractéristiques avec ceux qui ont fleuri dans différentes régions de Transoxiane parmi les ÿulama $\bar{a}^{1}$.

Le contexte politique complexe de l'écriture du texte, la riche intertextualité du Ta'rikh-i 'Ālimqul sont analysés en finesse par l'éditeur dans une très substantielle introduction. Timur Beisembiev met bien en lumière les intentions polémiques de Mullā Muhammad Yūnus et l'intertexte de son ouvrage, qui se veut une réponse à la publication en $1885 \mathrm{du}$ Ta'rikh-i shāhrukhỉ'. Le Ta'rikh-i 'Ālimqul se veut également une réponse, au tournant du $\mathrm{xx}^{\mathrm{e}}$ siècle, au défi politique alors représenté par les conséquences du soulèvement autochtone d'Andijan contre l'autorité russe en 1898 : se présentant comme un véritable mémorial du gouvernement Qipchāq à Kokand, l'ouvrage s'attache à dénoncer les aspects les plus négatifs du règne de l'aristocratie sédentaire personnalisée par Khudāyār Khān, et proteste de la loyauté envers l'administration russe de la faction réunie un temps autour de'Ālimqul.

6 De ce point de vue en particulier, la publication de ce texte, venant nuancer l'abondante littérature favorable à la mouvance de Khudāyār Khān, apporte une contribution essentielle à notre connaissance encore très fragmentaire des milieux politiques du khanat de Kokand, et plus largement de la Transoxiane dans les décennies précédant 
l'établissement de la domination russe. Il éclaire également le fonctionnement bien spécifique de la littérature biographique qui connut une floraison sans précédent dans l'ensemble de cette région, en liaison avec l'expansion coloniale de la Russie et les réactions vernaculaires à ce phénomène, à partir de la fin du xIX ${ }^{\mathrm{e}}$ siècle et jusqu'au milieu $\mathrm{du} \mathrm{xx}^{\mathrm{e}}$. Le Ta'rikh-i 'Ālimqul gagnera donc à être mis en perspective avec un certain nombre de textes biographiques ou autobiographiques contemporains, connus ou récemment sortis de l'ombre, comme par exemple, à propos de l'émirat de Boukhara, le « Journal » de l'éminent juriste et polygraphe Muhammad Šaríf Sadr-i Ziyā (1867-1932)².

7 Cette source majeure, autobiographie de Ziyā portant sur la période qui sépare la mort de son père en 1889 du lancement de la collectivisation quarante ans plus tard, est également appelée à prendre place parmi les principales sources de l'histoire de l'Asie centrale sous la domination russe, en dépit de son caractère hautement problématique (dû notamment au fait que, loin de constituer un recueil de "souvenirs quotidiens", le Rūznāma a été réécrit par Ziyā à partir de 1918, après l'incendie de sa bibliothèque et la destruction d'un manuscrit antérieur). L'apport de cette édition est à mettre en perspective avec l'étude, en cours, des nombreux autres textes de Ziyā sur lui-même et sur ses ascendants immédiats ${ }^{4}$.

\section{NOTES}

1. On trouvera de passionnants éléments de comparaison avec l'écriture de l'histoire par un représentant des umarā dans : Franz Wennberg, An inquiry into Bukharan Qadimism : Mìrzā Salìmbik, Berlin, Klaus Schwarz Verlag, 2002, 73 p. (Anor : 13).

2. Déjà étudié par Beisembiev: T. K. Beisembiev, Ta'rih-i Šahruhi kak istoričeskij istočnik (La "Chronique de Shāh Rukh» comme source historique), Alma-Ata, Izdat. Nauka Kazahskoj SSR, 1987.

3. Rūznāme-ye Sadr-e Ziyā. Vaqāye‘-negārī-ye tahavvolāt-e siyāsi-ejtemā‘ ì-ye Bokhārā-ye Šarîf teyy-e nìme-ye pāyānī-ye emārat-e khānāt-e Manghīt bar asās-e yāddāšthā-ye rūzāne-ye "Šarīf Jān Makhdūm Sadr-e Ziyā » (Le Journal de Sadr-e Ziyā. Une chronique des événements politiques et sociaux de Boukhara la Vénérable, dans la seconde moitié de l'émirat des khans Manghit, sur la base des souvenirs quotidiens de "Šarîf Jān Makhdūm Sadr-e Ziyā »), édition, introduction et apparat critique par Mohammad Jān Šakūrī Bokhārāyī, Téhéran, Markaz-e asnād va khadamāt-e pažūhešī, 1382[/2003], XI-500 p. (Majmū'e-ye Īrān va Māvarā al-nahr, 3); voir mon compte rendu de cet ouvrage dans Abstracta Iranica, 26 (2003), sous presse.

4. Voir sur ce point S. A. Dudoignon, «Les «tribulations » du juge Ziyā. Histoire et mémoire du clientélisme politique à Boukhara, du protectorat russe à la collectivisation (1868-1929) », Annales (H.S.S.), 5-6, sept.-déc. 2004, p. 1095-1135. 